\title{
Supervisory Monitoring Scheme: Implication to Teaching and Learning
}

\author{
Nilda V. San Miguel ${ }^{\mathrm{a}}$, Elymar A. Pascual ${ }^{\mathrm{b}}$ \\ elymarpascual@ rocketmail.com \\ ${ }^{a}$ Department of Education, Lumban District, Laguna, Philippines, 4014 \\ ${ }^{b}$ Department of Education, Nagcarlan District, Laguna, Philippines, 4002
}

\begin{abstract}
This study focused on determining the impact of supervisory monitoring scheme, particularly classroom observation, to the learners' performance. Forty-two teachers from 10 elementary schools in the District of Victoria, Laguna, Philippines became part of the study by undergoing classroom observations and answering the survey questions pertaining to the (1) teaching-and-learning process, (2) learners' behavior, (3) teachers' and learners' enthusiasm, and (4) effect to learners' performance. The authors made use of qualitative technique in doing research as responses to qualitative questions were recorded, sorted and analyzed. Themes were developed in the responses of teachers as situations with and without classroom observations are compared and contrasted. For teaching-and-learning process, it was found out that supervisory monitoring aid in the realization of proper teaching-and-learning process. The flow of teaching becomes smooth for four reasons: (1) the teacher is directed by guiding principles in teaching, (2) the teacher makes the session a learner-centered encounter, (3) the teacher develops lesson from previously known facts to discovery of new knowledge, and (4) the teacher follows strengthening of knowledge through the fixing skill in the application, evaluation and enhancement part of the lesson. For learners' behavior, it was found out that classroom supervision is a classic solution to problems arising from learners' misbehavior. When there is supervisory monitoring, five things were observed: (1) learners avoid disruptive behavior, (2) they perform at their utmost, (3) they choose the words that they will contribute to the discussion, (4) they participate actively, and (5) they display due respect to the teacher and the observer. For learners' and teachers' enthusiasm, it was found out that supervision and monitoring are good machineries for teachers and learners to work harder and sustain energy. Enthusiasm of teachers and learners were seen to be at high level when there is classroom observation because of three reasons: (1) the teachers are well-prepared, (2) the needed materials are available on hand, and (3) the learners look forward for group work and fun activities. And for the impact of classroom observation to learners' performance, it was found out that classroom climate changes when there is classroom observation. Learners' perform well when there is classroom observation for four reasons: (1) the lively climate produce when there is classroom observation, (2) the respect of learners both to the teacher and the higher authority present, (3) the preparation of the teacher that makes learners participate actively, and (4) the energy and enthusiasm of the teacher that influences learners' response. Recommendations to sustain the impact of classroom observation to learners' performance were given to school heads, master teachers, classroom teachers, advisers, parents and community.
\end{abstract}

Key words: behavior; classroom observation; enthusiasm;, learner; monitoring, performance; supervision

\section{Introduction}

Learners' pace was said to be dependent upon the direction of the teacher-facilitator, and it is the 
permeating idea nowadays. With the debut of the new Results-based Performance Management System Philippine Professionalization Standard for Teachers (RPMS-PPST) this school year 2018-2019, it has become a silver-lining for both the school heads and subordinates. Positive and negative response with this new method of classroom observation has been gathered to study the acceptance of teacher with this new way of monitoring. With the teachers inviting the school head, they can prepare well and classroom observation turns out to be a formal demonstration teaching to highlight best practice. On the other side, there has been news of depression resulting from the introduction of this new system.

Is there a difference in the performance of learners when there is no formal classroom observation and when there is a formal one? Does being prepared help a lot in boosting the confidence of the learners in participating in classroom discussion? Do learners got intimidated to participate when there are observers inside the classroom, or are they more motivated? This and more other concerns about supervisory monitoring scheme will be dealt with in this study.

\subsection{Background of the Study}

Secretary Briones signed into policy DepEd Order No. 42, S. 2017, which is known as The National Adoption and Implementation of the Philippine Professional Standards for Teachers. The policy states, among others, that the PPST "shall be used as a basis for all learning and development programs for teachers." The PPST identifies what teachers are expected to know, be able to do, and value in their profession. This national order is designed to be adopted for teachers alongside with the general annual evaluation for all government employees under the Results-based Performance Management System (RPMS).

The Department of Education is committed to supporting teachers' continuing professional development. A major aspect or tool of the Results-based Performance Management System-Philippine Professional Standards for Teachers (RPMS-PPST) is the Classroom Observation Tool (COT). The classroom observation is a supervisory moniroting scheme and a special gauge in ensuring quality teaching. Under the Republic Act 10533, underwise known as the Enhanced Basic Education Law of 2013, or the K to 12 Law, three important aspects of classroom observation are highlighted: (1) a process of providing feedback to a teacher's classroom practice, (2) encourages teachers to reflect and develop self-awareness about their own practice, and (3) provides evidence of actual teacher performance, their strenghes and ares of improvement. The RPMS Manual of 2018 indicates four classroom observation for one entire school year for each teacher should be done, i.e., one formal classroom demonstration per quarter in a school year. These classroom observations has three phases; the pre-obsertation conference, the classroom observation, and the postconference. Question arises whether the behavior of the learners, enthusiam of both teacher and learners, the teaching-and-learning process, and the performance of learners differ when there is classroom observation and when there is classroom observation. These aspects were investigated in this research.

\subsection{Theoretical Framework}

Researches have not yet explored on the direct impact of supervisory monitoring scheme or classroom observation on the behavior, enthusiasm and performance of learners inside the classroom. Nevertheless, the model of Forsyth and Hoy (2017) shows how the supervisory opportunities and constraints get into the scene of transformational process. It has five major elements: the teacher, teaching task, student, classroom climate and formal classroom organization. It is seen that supervisory aspect has something to do with all of these five elements, and that includes the students and their performance. The performance output can be seen to differ between expected and actual when there is supervisory monitoring because the framework is seen to be a cycle in which, after classroom supervision, feedback is broadcasted and the interval of classroom supervisions allows for the translation of actual outcome into becoming expected outcome. 


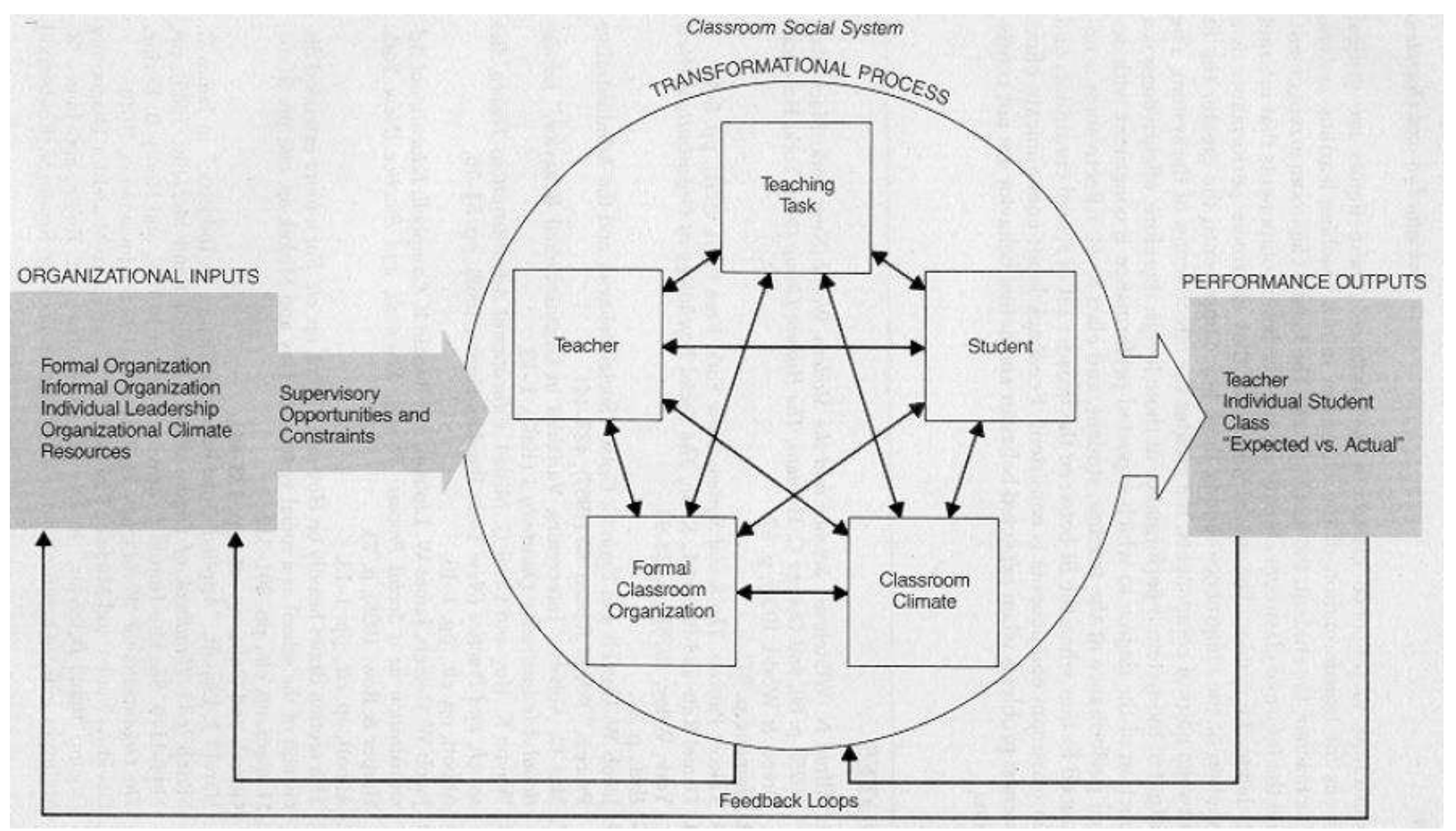

Fig. 1. The classroom performance model

\subsection{Conceptual Framework}

This study evolved on the concept of impact of supervisory monitoring, particularly on classroom observation, to the behavior, performance and enthusiasm of learners and teachers. The figure of the slopes of the mountain shows the possibility of heightened or degrading teaching-and-learning process in the conduct of classroom observation. The notion that the learner's behavior, enthusiasm and performance is of high level during supervisory monitoring can be seen in the figure, and the reverse is shown when there is no classroom observation from the school head or delegated authority.

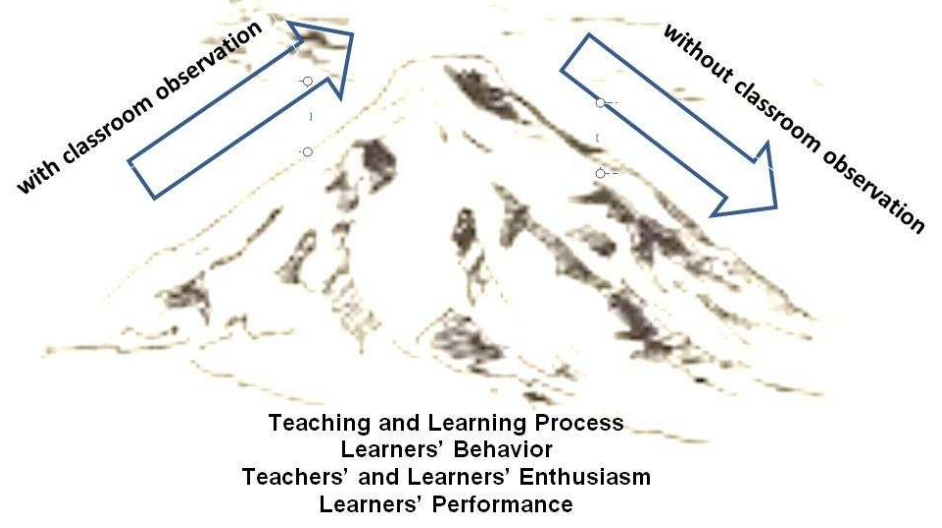

Figure 2. The teaching and learning process with and without classroom bbservation 


\subsection{Statement of the Problem}

This present study will delve into the concept of classroom observation and its effect to the teaching and learning process in Masapang Elementary School.

Specifically, it will seek to answer the following questions:

- How does the teaching-and-learning progress inside a classroom with and without classroom observation?

- What can be said about the learners' behaviour with and without supervisory observation?

- How will the enthusiasm of the teachers' and learners' be described with and without school head's monitoring on classroom teaching?

- Are learners' performance affected by supervisory monitoring schemes?

\subsection{Significance of the Study}

Both the teacher and the learners will be benefitted in this study. Risk is not a permeating factor because the formal classroom observation is mandated by the new RPMS-PPST of the Department of Education. The teachers selected are coming from the pool of key teachers, performers, and are promising in terms of performance. There are no emotional or relational biases. The selection is purely professional. Teachers will be informed beforehand that they are the representative teacher for a specific grade level. COT rating of teachers will not be revealed here because the focus is performance of learners.

\subsection{Scope and Limitation}

This study was conducted during the first and second quarter of the school year 2019-2020 in Masapang Elementary School, Victoria, Laguna, Philippines. The result that came out of this study encompasses only the scenario found in elementary schools because the teachers interviewed are all elementary teachers. The supervisory monitoring scheme that this study investigated is the classroom observation, which, under the Results-based Performance Management System - Philippine Professional Standards for Teachers (RPMS-PPST), should be done for each teacher four times in an entire school year. Classroom observations are announced because the teachers themselves are the ones inviting the observers (school head and/or master teachers) for a formal teaching demonstration. The classroom observations passed through pre-conference and post-conference. All the ratings that proceed form the classroom demonstrations becomes the basis for the Individual Performance Commitment Ratings which is evaluated and checked during midyear and at the end of the school year.

\section{Related Literature}

This part of the paper highlights the studies and writings published that has direct or indirect connection to the topic discussed in this research.

\subsection{Supervisory Monitoring and Classroom Observation}

On the aspect of school supervision, Onasanya (2017) said, "Educational activities need supervision and inspection to achieve educational objective. Supervision and inspection are good machineries to up-grade teachers into required standard. Teachers need supervision and inspection to work harder no matter what their level of experience and devotion are. Without supervision both teachers and school administrators backslide rapidly in their performance."

Behlol (2011) made a study on supervision and supervisory practices. It was conducted to find out the practices and problems of supervisors working at primary school level in Pakistan. It revealed that 
supervisors do not delegate the responsibilities to the staff to perform the educational making process. As a result, the team members will not put their all out efforts in the activity and take it as burden. It $s$ recommended that a training programme for the supervisors working at Primary level may be designed and launched to improve their knowledge, skills and attitude to perform their duties as a facilitator, guide, motivator, helper and the leader of the team.

Forsyth and Hoy (2017) in his book stated that "effective supervision in public schools is an elusive but fascinating activity, and much confusion and misapprehension surround the word "supervision" itself... Close supervision was a classic response to production and control problems: it was management's attempt to manipulate and control subordinates. It should not be surprising, then, that a good many teachers view supervisions as simply another layer in the bureaucratic structure designed to watch and control their actions."

Treslan (2017) examined the learning organization dimension of schools. His purpose is to identify implications for specific components of supervision, namely, knowledge, interpersonal/technical skills and task areas. The supervisory process is argued to be significantly affected by a learning organization presence, creating additional leadership role responsibilities.

The above-mentioned readings contribute to the development of concepts related to the present study, specially the importance of monitoring and supervision.

\subsection{Learners' Performance}

Haahr (2005), in explaining student performance as evidenced from the international PISA, TIMSS and PIRLS surveys, said that a range of assessment methods can be used in order to assess students' academic progress: Standardized tests, the assessment of student portfolios, judgmental ratings carried out by teachers, regular teacher-developed tests and assessments of student assignments, projects, and homework.

In a synthesis relating to achievement, Hattie (2009) said, "It is students themselves, in the end, not teachers, who decide what students will learn. Thus we must attend to what students are thinking, what their goals are, and why they would want to engage in learning what is offered in schools."

Anand (2009) conducted a study on students' performance in two semesters of Cell Biology course. Teaching strategies, behaviors, and pre-course variables were analyzed with respect to students' performance... Chi-square tests of independence showed that completion of chemistry requirements, passing the laboratory component of Cell Biology, homework, and attendance were related to passing our course. Logistic regression showed that perfect attendance followed by GPA, were the most important factors associated with passing the course.

In a study made by Katsikas (2010), the academic and social profiles of 867 students, studying in a university of Economic and Social Studies, are analysed by means of Ordinary Least Squares and Quantile Regression Methods. Study showed that working students do not achieve lower grades than non-working peers.

Yusuf (2017) focused on the subject social studies. The researcher's study revealed that there is a significant effect of a teaching method on academic performance of students in social studies. Second, there is a significant influence of family background on academic performance in social studies. Also, there is a significant effect of learning strategies on learning outcomes of students in social studies.

Martha (2009) made a connected study on this. It was designed to investigate the factors affecting academic performance of undergraduate students of Uganda Christian University (UCU). The findings revealed the existence of a significant relationship between students' A-level and Diploma admission points and academic performance, but there was no relationship between mature age points and academic performance. The findings also revealed that there was a significant relationship between parents' social economic status and academic performance and a significant relationship between former school background and academic performance.

Falsario's (2014) study focused on the relationship between classroom climate and student's 
academic performance. The respondents were the 123 fourth year Bachelor of Secondary Education and Bachelor of Elementary Education students taking the Teaching Profession. Study revealed that classroom climate to a certain extent has some influence on academic performance of students.

Wenglinsky (2001) found out in his study that the effects of classroom practices, when added to those of other teacher characteristics, are comparable in size to those of student background, suggesting that teachers can contribute as much to student learning as the students themselves.

All the above-mentioned readings are related to the present study because they bring about what has been studied in academic performance and its relation to different factors.

\section{Research Design and Methodology}

This part of the study discusses the research design, respondents, data gathering procedure, data gathering instrument, ethical consideration, and data analysis for this study.

\subsection{Research Design}

This study employed a qualitative approach in doing research. Creswell (2003) describes qualitative research in three ways which makes this design different from quantitative research: (a) makes knowledge claims based on constructivist perspectives, (b) uses strategies of inquiry, and (c) collects open-ended emerging data with the primary aim of developing themes from the data. Survey questions were given to the teacher concerned so that the researcher can investigate on their perception on the different aspects like teaching-and-learning process, learners' behavior, and teacher and learners' enthusiasm.

\subsection{Respondents}

Ten elementary schools in the district of Victoria, Laguna, Philippines were selected to be part of this study. From the 10 public elementary schools, 42 teachers were selected. The distribution of their position or designation was shown on the table. The grade levels that the 42 teachers were handling are scattered from Grade 1 to Grade 6. These teachers are randomly selected.

Table 1. Position distribution of teacher-respondents

\begin{tabular}{|c|c|}
\hline Position/Designation & Frequency \\
\hline Teacher I & 9 \\
\hline Teacher II & 4 \\
\hline Teacher III & 16 \\
\hline Master Teacher I & 11 \\
\hline Master Teacher II & 2 \\
\hline Total & $\mathbf{4 2}$ \\
\hline
\end{tabular}

\subsection{Data Gathering Procedure}

This data will make use of both quantitative and qualitative data. The sources are the result of quizzes of the learners' and teachers' response to survey questions. To specify, here is the plan for every item in the Statement of the Problem (SOP).

To answer ethical concerns that has direct and indirect relation to the present study, the seven-point ethical issues are answered here:

- Social value - Since the supervisory monitoring method to be used is the formal classroom observation through teacher's invitation to the principal, the relationship and social value is protected. The element of 
surprise is avoided. Teachers are expecting, and therefore ready for the principal's visit.

- Scientific validity - The researcher asked the help of an expert to scientifically treat the data using Word Cloud software. Scientific validity will be attained because there will be no jumping into conclusion that will happen. Only conclusion which was backed up with frequencies of word appearance in responses were presented in this research.

- Fair subject selection - The teachers selected were coming from the pool of key teachers, performers, and are promising in terms of performance. There were no emotional or relational biases. The selection was purely professional.

- Favorable risk-benefit ratio - Both the teacher and the learners were benefitted in this study. Risk was not a permeating factor because the formal classroom observation was mandated by the new RPMS-PPST of the Department of Education in the Philippines.

- Independent review - Analysis and interpretation of data were carefully done. Only the plain data ore responses treated. The responses of the teachers, whether positive or negative, were reflected in this study.

- Informed consent - Teachers were informed beforehand that they would be part of this study and therefore, data would collected from them through their responses to survey questions.

- Respect for enrolled subject - Classroom Observation rating of teachers was not revealed here because the focus was behavior, performance, and enthusiasm of learners and teachers.

\subsection{Data Gathering Instrument}

To answer the problems posted at the beginning of the study, survey questions were given to the 42 teachers after two times of undergoing classroom observation from their school heads. The questions were cited here:

- How do you see the teaching and learning process differs when there is not classroom observation?

- How do you see the teaching and learning process differs when there is classroom observation?

- What can you say about the children's behaviour during class discussion when there is no supervisory monitoring?

- What can you say about the children's behaviour during class discussion when there is supervisory monitoring?

- Would you describe the level of teacher and learners' enthusiasm when there is no formal demonstration teaching?

- Would you describe the level of teacher and learners/ enthusiasm when there is formal demonstration teaching?

- Do you think classroom observation of school heads affect learners' performance? Why?

\subsection{Data Analysis}

To be able to analyze the data gathered, online software that generates Ordinary Word Cloud, 2D Physics Word Cloud, and General Statistics (for mostly appearing words) were used. Responses were encoded in the software and it gave an output that can reveal themes, and finally answer the questions posted for this study. Internal analysis was generated based on revealing themes. Findings were also checked against related readings to generate external analysis.

\section{Presentation, Interpretation and Analysis of Data}

This part of the study presents the generated result from the responses of elementary school teachers. Interpretation follows based on the table of mostly appearing words and the word cloud corresponding to each table. Finally, internal and external analyses were employed to analyze the findings. 


\subsection{Teaching-and-Learning Process without Supervisory Monitoring}

The table shows the top 10 mostly appearing words in the responses of 42 teachers regarding the first survey question. The words were written in decreasing number of appearances as shown in their responses.

Table 2. Top 10 mostly appearing words; teaching-and-learning process without supervisory monitoring

\begin{tabular}{|c|c|}
\hline No. & Word \\
\hline 1 & Teachers \\
\hline 2 & time \\
\hline 3 & students \\
\hline 4 & Say \\
\hline 5 & given \\
\hline 6 & process \\
\hline 7 & informal \\
\hline 8 & conscious \\
\hline 9 & free \\
\hline 10 & use \\
\hline
\end{tabular}

The succeeding word cloud shows the permeating ideas that can be seen from the responses of 42 elementary school teachers to the first question. These were followed by 5 themes and analyses.

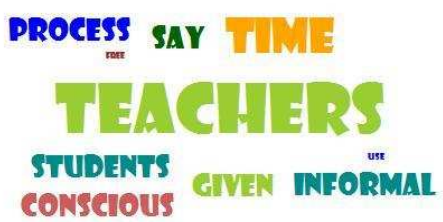

Fig. 3. Word cloud; teaching-and-learning process without supervisory monitoring

- Teachers - When there is no classroom observation, the delivery of knowledge is teacher-centered. The control mainly resides on the teacher and there is less input from the learners. Also, teachers direct the topic and he may shift from one competency to another, as is needed for the day. Or it can also happen that there are more than one competencies being tackled in a single session.

- Time - Time management is not controlled. The teacher can have the competency discussed in one sitting or two meetings. The teacher is able to adjust based on the pacing of the learners.

- Students - Students do not behave well. This can be attributed to the fact that there is already deep acquaintance between the teacher and the learners. The learners somehow have attained a level of friendly relationship with the teacher, thereby losing control sometimes during times of boredom.

- Informal - The teaching approach is informal. There are moments of teacher talk when the teacher is able 
to inject stories and funny moments to make the session light.

- Conscious, free - Teachers are not conscious of time and many other aspects of teaching. Review and motivations maybe neglected because of time constraint wherein the teacher needs to meet the delivery of competencies at a given timeframe within a quarter of school year.

\subsection{Teaching and Learning Process under Supervisory Monitoring}

The table shows the top 10 mostly appearing words in the responses of 42 teachers regarding the second survey question. The words were written in decreasing number of appearances as shown in their responses.

Table 3. Top 10 mostly appearing words; teaching-and-learning process under supervisory monitoring

\begin{tabular}{|c|l|}
\hline No. & \multicolumn{1}{|c|}{ Word } \\
\hline 1 & teaching \\
\hline 2 & conscious \\
\hline 3 & time \\
\hline 4 & more \\
\hline 5 & well \\
\hline 6 & process \\
\hline 7 & step \\
\hline 8 & Focuses \\
\hline 9 & things \\
\hline 10 & needed \\
\hline
\end{tabular}

The succeeding word cloud shows the permeating ideas that can be seen from the responses of 42 elementary school teachers to the second question. These were followed by 5 themes and analyses.

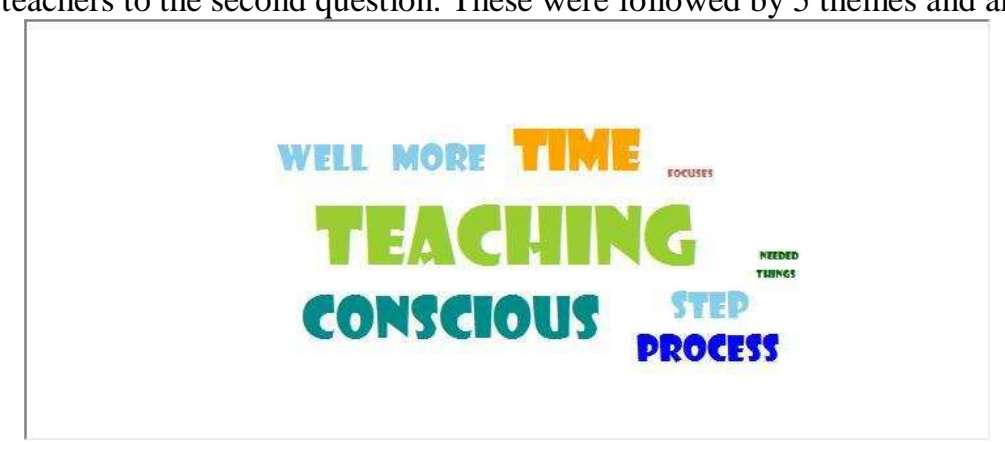

Fig. 4. Word cloud; teaching-and-learning process under supervisory monitoring

- Teaching - The teaching is formal and focuses on the things that are needed to be learned or the competencies needed to be attained. All parts of the teaching and learning process from review, motivation, discussion, application, evaluation and enhancement are dealt with. 
- Conscious - Teachers are conscious of learners' participation and the step-by-step procedure in teaching is carefully executed. Teachers avoid teacher-talk and always apply positive discipline.

- Time - Time management is being taken cared. All parts of the teaching-and-learning process executed with time frame and the teacher sets rules and regulations to meet the required performance and competency.

- More - There is more participation from learners. Teaching becomes learner-centered. Discovery of knowledge is more applied than just lecture and spoon-feeding.

- Well - Lesson plan is well-prepared lesson plan and instructional materials are carefully crafted. Activity cards, worksheets and other materials are ready beforehand, therefore, the teaching execution is natural.

The implication in the findings of this study was the same as that of Treslan (2017). For him, supervisory process significantly affects learning because of the creation of additional leadership role responsibilities. Through the presence of higher authority during the teaching-and-learning process, the flow of teaching becomes smooth because the teacher is directed by guiding principles in teaching - making the session a learner-centered encounter, development of lesson from previously known facts to discovery of new knowledge, and fixing of skill through the application, evaluation and enhancement part of the lesson.

\subsection{Learners' Behavior without Supervisory Monitoring}

The table shows the top 10 mostly appearing words in the responses of 42 teachers regarding the third survey question. The words were written in decreasing number of appearances as shown in their responses.

Table 4. Top 10 mostly appearing words; learners' behavior without supervisory monitoring

\begin{tabular}{|c|l|}
\hline No. & \multicolumn{1}{|c|}{ Word } \\
\hline 1 & want \\
\hline 2 & difference \\
\hline 3 & freely \\
\hline 4 & children \\
\hline 5 & classroom \\
\hline 6 & observation \\
\hline 7 & proactive \\
\hline 8 & paying \\
\hline 9 & attention \\
\hline 10 & Express \\
\hline
\end{tabular}

The succeeding word cloud shows the permeating ideas that can be seen from the responses of 42 elementary school teachers to the third question. These were followed by 5 themes and analyses. 


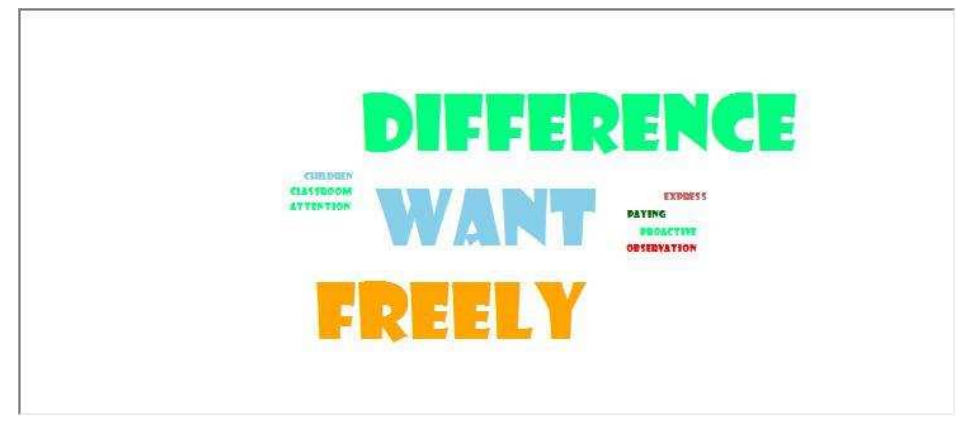

Fig. 5. Word cloud; learners' behavior without supervisory monitoring

- Want - Learners do what they want to do, not what is expected. They feel they are at-ease with their teacher around, especially when the parent-child relationship is already built.

- Difference - Learners are not conscious on their manner of responding to the teacher. It is different when the school head is around. Sometimes, learners answer in chorus. They don't feel intimidated.

- Freely - Since learners got accustomed with day-to-day meeting with the teacher, they freely do and say what they want to. They are a bit relaxed and they have that notion of being at home in classroom. They can have time to play and time to mingle with others.

- Proactive - Learners not just respond to situation but they create or control situation. This can be seen as positive when there is no supervisory monitoring, but can also be negative when learners' proactive behavior are not controlled or guided.

- Paying, attention - Some don't pay attention to the classroom discussion. They also have tantrums, needing special attention which should be dealt immediately, causing distraction in the teaching-and-learning process.

\subsection{Learners' Behavior under Supervisory Monitoring}

The table shows the top 10 mostly appearing words in the responses of 42 teachers regarding the fourth survey question. The words were written in decreasing number of appearances as shown in their responses.

Table 5. Top 10 mostly appearing words; learners' behavior under supervisory monitoring

\begin{tabular}{|c|l|}
\hline No. & \multicolumn{1}{|c|}{ Word } \\
\hline 1 & classroom \\
\hline 2 & observation \\
\hline 3 & Depend \\
\hline 4 & teachers \\
\hline 5 & discipline \\
\hline 6 & learners \\
\hline 7 & bored \\
\hline
\end{tabular}




\begin{tabular}{|c|l|}
\hline 8 & Same \\
\hline 9 & Some \\
\hline 10 & pretending \\
\hline
\end{tabular}

The succeeding word cloud shows the permeating ideas that can be seen from the responses of 42 elementary school teachers to the fourth question. These were followed by 5 themes and analyses.

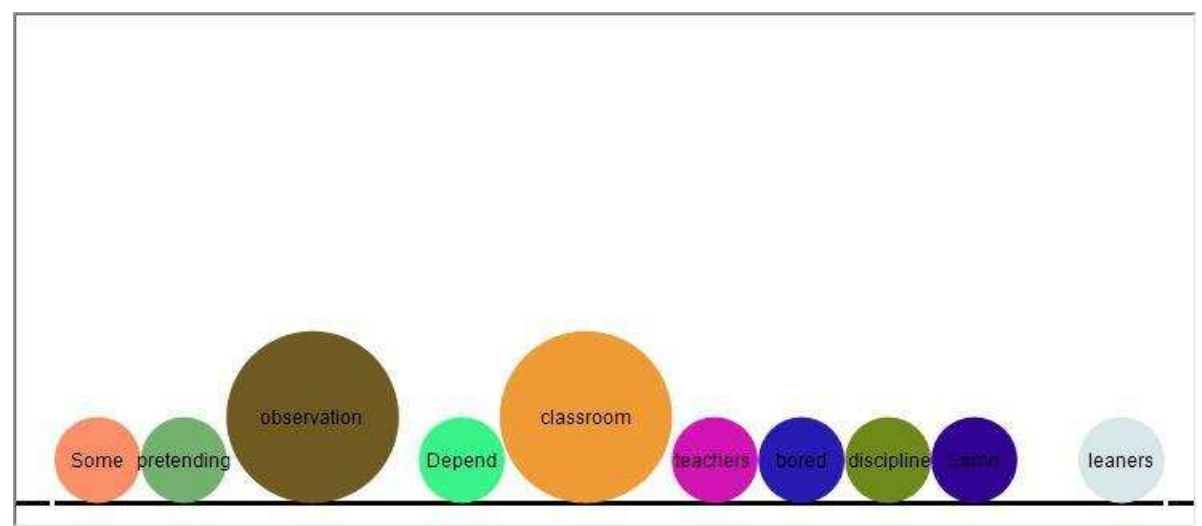

Fig. 6. Word cloud; Learners' behavior under supervisory monitoring

- Classroom - Learners' participate on maintaining classroom cleanliness and discipline. They sense a higher authority aside from their teacher inside the classroom, and so their consciousness on classroom discipline is heightened.

- Depend, discipline - Discipline does not just depend on the teacher. The presence of the visitor, the school head, makes the class in the disciplined mood. Students display a behavior of pleasing those who have authority over them, especially in the academic setting.

- Learners - Learners feel that they are the ones being observed, so they are attentive. But the fact that the behavior and strategy of the teacher is being noted by the principal is known to them, that is why, they also cooperate in being part of the success of the teacher.

- Bored - No moments of boredom are seen from learners; they all seem to participate. They have some fear of being called, not being able to answer, and the scenario being noted by the principal.

- Some, pretending - Some pretends to listen, and others are really attentive. Since the words from the teacher are carefully crafted and formal in nature, some learners which are not acquainted with it behave, having the feeling of being in a special setting to study a lesson for the day.

Forsyth and Hoy (2017) was correct that close supervision was a classic response to the control of problems. When there is supervisory monitoring, specifically classroom observation, learners avoid disruptive behavior, perform at their utmost, choose the words that they will contribute to the discussion, participate actively, and display due respect to the teacher and the observer.

\subsection{Teacher and Learner Enthusiasm without Supervisory Monitoring}

The table shows the top 10 mostly appearing words in the responses of 42 teachers regarding the fifth survey question. The words were written in decreasing number of appearances as shown in their 
responses.

Table 6 . Top 10 mostly appearing words; teacher and learner enthusiasm without supervisory monitoring

\begin{tabular}{|c|l|}
\hline No. & \multicolumn{1}{|c|}{ Word } \\
\hline 1 & enthusiasm \\
\hline 2 & low \\
\hline 3 & teachers \\
\hline 4 & more \\
\hline 5 & excited \\
\hline 6 & teach \\
\hline 7 & boundaries \\
\hline 8 & Sometimes \\
\hline 9 & active \\
\hline 10 & Depend \\
\hline
\end{tabular}

The succeeding word cloud shows the permeating ideas that can be seen from the responses of 42 elementary school teachers to the fifth question. These were followed by 5 themes and analyses.

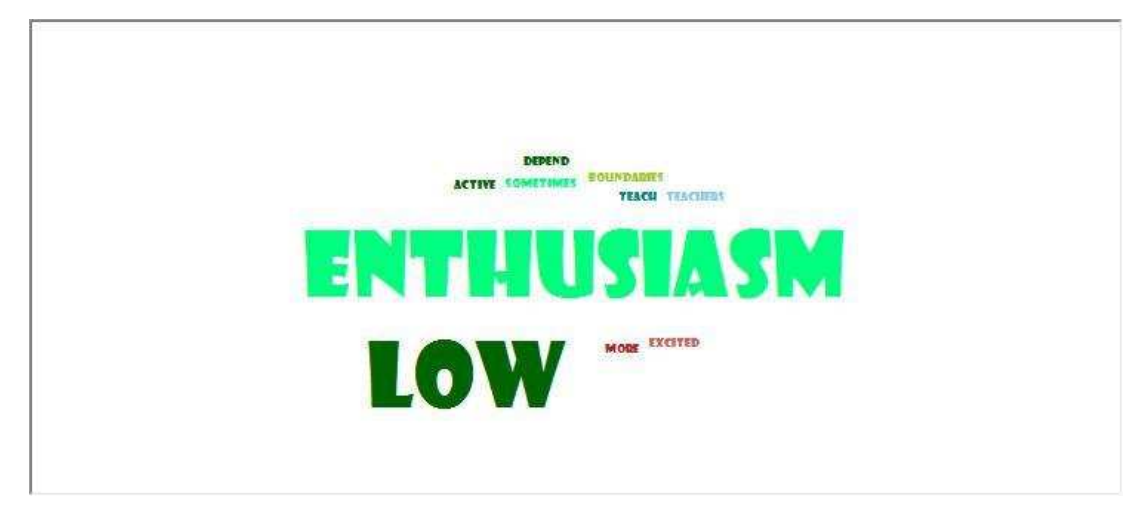

Fig. 7. Word cloud; learners' behavior under supervisory monitoring

- Enthusiasm, low - Low enthusiasm is seen from learners and teachers' energy is affected by learners' low response. Still, others are energetic because of the freedom to express their ideas without a higher authority observing them.

- More - More time is wasted in disciplining learners. The teaching-and-learning process is halted by learners' misbehavior, affecting others enthusiasm to learn naturally and in a freely-flowing manner.

- Excited - Some learners, and sometimes the teacher as well, are excited and not feel pressured because there is no supervisory monitoring from master teachers or school heads. The environment is being controlled 
by the teacher on whatever his strategy is and the manner on how he delivers the lesson.

- Boundaries - Boundaries are set aside making the environment free for learning, but sometimes this gears up to undisciplined classroom. Enthusiasm is seen on the aspect that the learners are playful, and the teacher can go along with the learners' pace.

- Active - Some learners are seen to be active because the teacher is able to set up the environment in a way that they can always ask questions and contribute on the development of knowledge. This requires, on the part of the teacher, flexibility on the designed lesson plan for the day.

\subsection{Teacher and Learner Enthusiasm under Supervisory Monitoring}

The table shows the top 10 mostly appearing words in the responses of 42 teachers regarding the sixth survey question. The words were written in decreasing number of appearances as shown in their responses.

Table 7. Top 10 mostly appearing words; teacher and learner enthusiasm under supervisory monitoring

\begin{tabular}{|c|l|}
\hline No. & \multicolumn{1}{|c|}{ Word } \\
\hline 1 & Enthusiasm \\
\hline 2 & greatly \\
\hline 3 & observed \\
\hline 4 & Students \\
\hline 5 & teacher \\
\hline 6 & got \\
\hline 7 & nervous \\
\hline 8 & uneasy \\
\hline 9 & like \\
\hline 10 & recorded \\
\hline
\end{tabular}

The succeeding word cloud shows the permeating ideas that can be seen from the responses of 42 elementary school teachers to the sixth question. These were followed by 5 themes and analyses.

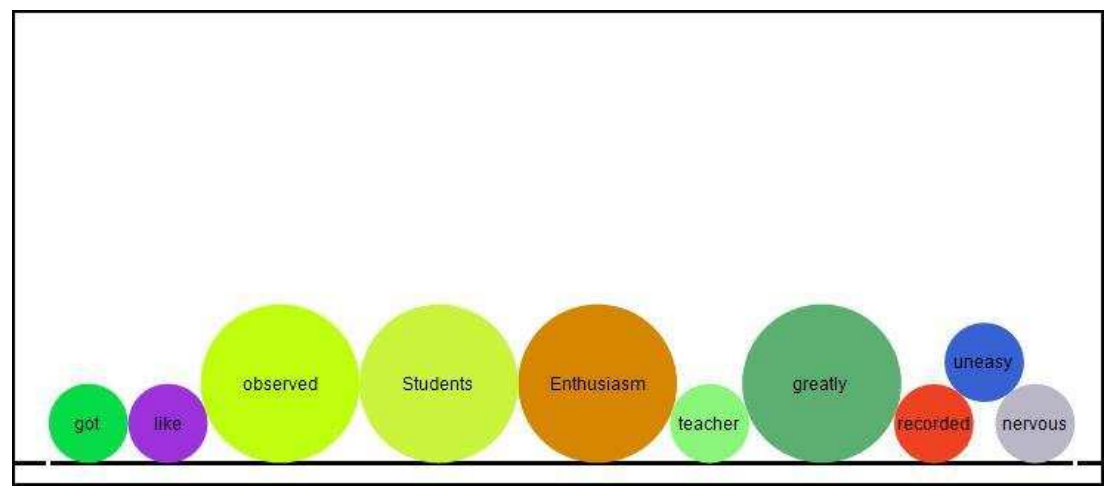

Figure 8. Word cloud; teacher and learner enthusiasm under supervisory monitoring 
- Enthusiasm, greatly, observed - Enthusiasm is greatly observed. The visiting personnel plus the prepared activity for the day makes the learners anticipating for motivational activity, fun games and rewards.

- Students - Students are almost $100 \%$ attentive. They avoid loitering because observers are around, unlike the usual day when the authority is just in front of the classroom.

- Teacher - Teacher is energetic because the supervisory monitoring requires for a formal teaching demonstration, and his skill and strategy is being noted. He has his lesson and materials prepared so the flow of teaching would be natural for him.

- Nervous - Into some extent, nervousness is seen from both teacher and learners. The idea of someone being around to give critics and evaluation gives tense to new and seasoned teachers.

- Uneasy - Though there is high level of enthusiasm, learners are conscious of their responses and performance. They are uneasy to contribute idea without prior readiness and careful evaluation of whatever the learners want to during classroom discussion. They feel they are not just evaluated by the teacher but by the higher authority in school as well.

The concepts of Onansaya (2017) supports the finding in this study that supervision and monitoring are good machineries for teachers and learners to work harder no matter what their level of experience and devotion are. Enthusiasm of teachers and learners were seen to be at high level when there is classroom observation because the teachers are well-prepared, the needed materials are available on hand, and the learners look forward for group work and fun activities. The uneasiness and nervousness felt by learners and teachers during classroom observation do not make the enthusiasm subside, rather, assist in maintaining classroom discipline and proper direction.

\subsection{Impact of Supervisory Monitoring to Learners' Performance}

The table shows the top 10 mostly appearing words in the responses of 42 teachers regarding the seventh survey question. The words were written in decreasing number of appearances as shown in their responses.

Table 8. Top 10 mostly appearing words; Impact of supervisory monitoring to learning

\begin{tabular}{|c|l|}
\hline No. & \multicolumn{1}{|c|}{ Word } \\
\hline 1 & level \\
\hline 2 & students \\
\hline 3 & performance \\
\hline 4 & participation \\
\hline 5 & high \\
\hline 6 & Pupils \\
\hline 7 & perform \\
\hline 8 & well \\
\hline 9 & showed \\
\hline 10 & disciplined \\
\hline
\end{tabular}


The succeeding word cloud shows the permeating ideas that can be seen from the responses of 42 elementary school teachers to the seventh question. These were followed by 5 themes and analyses.

\section{PARTICIPATION STUDENTS PUDils = LEVEL - PERFormaNCE}

Figure 9. Word Cloud; Impact of Supervisory Monitoring to Learning

- Level - Learners' level of performance is heightened. They perform better when there is supervisory monitoring rather than the usual day-to-day meeting with the subject teacher.

- Students, performance - Students become conscious of their performance because of the notion that the school head is also observing them. If their teachers are their second parents at home, so the school head is their grandparent who monitors them and requires respect and good behavior.

- Participation - Students' participation is increased. Because of the prepared group activity, fun games and other social activities, there is higher percentage of learner participation than when there is no supervisory monitoring.

- Showed - Learners tend to show their best which they sometimes don't show during ordinary day-to-day classroom discussion. They choose their words well, and they display their best behavior, at least for some students.

- Disciplined - Classroom is more disciplined. Learners are advised to show their utmost skill and display their good behavior because the principal or master teacher is around. They obey the teacher because of mutual respect that they have developed as teachers and learners.

Falsario's (2014) findings in his study support the findings in this study on the aspect of classroom climate. Classroom climate changes when there is classroom observation, thereby creating difference in the learners' performance, and that difference on the positive side. Learners' perform well when there is classroom observation because of the climate produce when there is classroom observation, their respect to both the teacher and the higher authority present, the preparation of the teacher that makes learners participate actively, and the energy and enthusiasm of the teacher being observed that influences learners' response.

\section{Conclusion, Recommendation and Reflection}

This portion of the study lines up the conclusions resulting from the findings gathered from the responses of teachers, the recommendations that are deemed to sustain the positive impact of supervisory monitoring, and the reflection of the authors regarding the issue and findings being discussed in this paper.

\subsection{Conclusion}

Four important things were discussed in this paper based on the themes generated from the responses 
of teachers on the issues being brought up the beginning of the study: (1) teaching-and-learning process with and without classroom observation, (2) learners' behavior with and without classroom observation, (3) learners' and teachers' enthusiasm with and without classroom observation, and (4) impact of classroom observation to learners' performance.

For teaching-and-learning process, it was found out that supervisory monitoring aid in the realization of proper teaching-and-learning process because of the creation of additional leadership role responsibilities that is visible when school heads are inside the classroom. Through the presence of higher authority during the teaching-and-learning process, the flow of teaching becomes smooth for four reasons: (1) the teacher is directed by guiding principles in teaching, (2) the teacher makes the session a learner-centered encounter, (3) the teacher develops lesson from previously known facts to discovery of new knowledge, and (4) the teacher follows strengthening of knowledge through the fixing skill in the application, evaluation and enhancement part of the lesson.

For learners' behavior, it was found out that classroom supervision is a classic solution to problems arising from learners' misbehavior. When there is supervisory monitoring, five things were observed: (1) learners avoid disruptive behavior, (2) they perform at their utmost, (3) they choose the words that they will contribute to the discussion, (4) they participate actively, and (5) they display due respect to the teacher and the observer.

For learners' and teachers' enthusiasm, it was found out that supervision and monitoring are good machineries for teachers and learners to work harder and sustain energy. Enthusiasm of teachers and learners were seen to be at high level when there is classroom observation because of three reasons: (1) the teachers are well-prepared, (2) the needed materials are available on hand, and (3) the learners look forward for group work and fun activities. The uneasiness and nervousness felt by learners and teachers during classroom observation do not make the enthusiasm subside, rather, assist in maintaining classroom discipline and proper direction.

And for the impact of classroom observation to learners' performance, it was found out that classroom climate changes when there is classroom observation, thereby creating positive difference in the learners' performance. Learners' perform well when there is classroom observation for four reasons: (1) the lively climate produce when there is classroom observation, (2) the respect of learners both to the teacher and the higher authority present, (3) the preparation of the teacher that makes learners participate actively, and (4) the energy and enthusiasm of the teacher that influences learners' response.

\subsection{Recommendation}

Through this study, it was clearly revealed that classroom observation does not necessarily need to create pressure among teachers and learners. But how would the good impact of classroom observation to learners' performance be sustained when classroom observation under the new RPMS-PPST set-up is just four classroom observations for the entire school year? The call for all teachers and educators to maintain the atmosphere during the classroom observation is now being laid down here.

- School heads should maintain regular monitoring and supervision outside classroom observation (CO). The Department of Education's mandate for schools heads to perform unannounced classroom observation like Situation-Task-Action-Result (STAR) observation and snoopervision should be regularly done because leadership visibility is important.

- Master teachers must seriously perform the conduct of pre-conference, classroom observation, and postconference so as to create a culture of excellence in terms of formal classroom demonstration. Add to this is the regular technical assistance/coaching through the dissemination of the use of the Modules accompanying the new RPMS-PPST which are designed to greatly aid teachers in performing their multi-faceted duties and responsibilities.

- Teachers religiously prepare lesson plan not just a requirement but a blueprint of the effective teaching- 
and-learning process, not just for classroom observation purposes but as a daily routine and a regular practice. Teacher should regularly uphold the duties and responsibilities of a public school servant with or without classroom observation. Advisers have all the materials they need from the RPMS tools. Example is the learners' cardex that would aid them in monitoring learners' progress and adapt their strategies with the learners' interests, strengths and weaknesses. The use of modules 1 to 12 for professional growth was carefully prepared for teachers to maintain professionalism, maximize the use of positive discipline, deal with learners' diversity, and many other topics that would equip proficient and highly proficient teachers.

- Parents and the community should be actively involved in school projects and programs, and in constant monitoring of their child's progress. Having this attitude gives enthusiasm for the teacher to continue to uphold the characteristics of an effective and efficient teacher. The partnership of school and community is a formidable weapon against mediocrity in education.

5. Future researchers are advised to extend endeavor in exploring the impact of classroom observation and other supervisory monitoring scheme to the performance of learners in the secondary level.

\subsection{Reflection}

In the outset of the pervading notion that the new RPMS-PPST set-up of the Philippine Education System creates pressure in terms of classroom observation, this study strengthens the belief of the researchers that it is not so. Rather, the innovation in the set-up clearly resides on the fact that the learners would be greatly benefitted. A positive mind would create a positive acceptance and response to the need of times. The youth of today are ever-changing in terms of their behavior, decisions, social interaction, ways and practices, and this calls for innovation in the education system as well. If education would not innovate, then it would be stagnant and would leave learners groping for their good future ahead of them.

Teachers touch the future by teaching, and therefore they need to prepare learners of today through their ways and needs. "It is students themselves, in the end, not teachers, who decide what students will learn. Thus we must attend to what students are thinking, what their goals are, and why they would want to engage in learning what is offered in schools." (Hattie, 2009) Teachers remain to be an agent of change for learners' behavior, thinking and direction. This does not mean that they will control the young minds, rather, they will set themselves as bridge so that learners can pass from a stage of mediocrity to a stage of readiness, from a stage of hopelessness to a stage of independency, from a stage of none-identity to a stage of uniqueness and worth.

\section{References}

Anand, S. and Soto, J. G. (January 2009). Journal of the Scholarship of Teaching and Learning, Vol. 9, No. 1, Factors influencing academic performance of students enrolled in a lower division Cell Biology core course, pp. 64-80.

Behlol, M.G. (Nov. 1, 2011). Concept of Supervision and Supervisory Practices at Primary Level in Pakistan, PMAS-Arid Agriculture University, Rawalpindi, Pakistan

Department of Education Order No. 42, s. 2017. (2017). "The National Adoption and Implementation of the Philippine Professional Standards for Teachers", Manila, Philippines

Falsario, H.N., Muyong, R.F., Nuevaespaña, J.S. (March 6-8, 2014). Classroom Climate and Academic Performance of Education Students, Southern Iloilo Polytechnic College, WVCST Miagao Campus Presented at the DLSU Research Congress 2014, De La Salle University, Manila, Philippines

Forsyth, Patrick B., Hoy, Wayne K., (2017). "Effective Supervision: Theory into Practice”, Rutgers University, New Brunswick, New Jersey, United States.

Haahr, J. H., Hansen, M. E., Jakobsen, S. T., Nielsen, T. K., (November 2005). Explaining Student Performance Evidence from the international PISA, TIMSS and PIRLS surveys Danish Technological Institue,

Hattie, J. (2009). Visible Learning: A Synthesis of Over 800 Meta-Analysis Relating to Achievement. New York: Routledge.

Katsikas, E., Panagiotidis, T. (October 2010). Status and Academic Performance: an approach of the quality determinants of university studies in Greece, Hellenic Observatory Papers on Greece and Southeast Europe, The Hellenic Observatory, the European Institute.

Martha, K. (December 2009). Factors Affecting Academic Performance of Undergraduate of Students at Uganda Christian University, by 
Kyoshaba Martha, BBA (UCU), 2005, Dissertation submitted to Graduate School in Partial Fulfilment of the Requirements for the Award of the Degree of Master of Arts in Educational Management of Makerere University.

Onasanya, S.A., (2017). The concept and practices of supervision/inspection in Kwara State Public Primary Schools, Department of Science Education, Faculty of Education, University of Ilorin, Ilorin, Nigeria.

Republic Act 10533. (2013). "Enhanced Basic Education Law, or the K to 12 Law", Manila, Philippines

Results-based Performance Management System Manual. (2018). Manila, Philippines

Treslan, D.L. (2017). Educational Supervision in a "Transformed" School Organization, Faculty of Education Memorial University of Newfoundland.

Wenglinsky, H. (September 2001). Teacher Classroom Practices and Student Performance: How Schools Can Make a Difference, Educational Testing Center, Statistics and Research Division, Princeton, NJ. 